\title{
Axial Compression of Glass Fiber Tube-Gangue Concrete-Steel Tubular Hollow Columns
}

\author{
Ni Zhang $\mathbb{D}^{1}{ }^{1}$ Chenyang Zheng, ${ }^{1}$ Zhongwei Zhao $\triangle{ }^{1},{ }^{1}$ and Bo Yang ${ }^{2}$ \\ ${ }^{1}$ School of Civil Engineering, Liaoning Technical University, Fuxin 123000, China \\ ${ }^{2}$ Chaoyang Investment and Project Construction Service Center, Chaoyang 122000, China \\ Correspondence should be addressed to Ni Zhang; 418688814@qq.com and Zhongwei Zhao; zhaozhongwei@lntu.edu.cn
}

Received 7 March 2021; Accepted 21 May 2021; Published 30 May 2021

Academic Editor: Hongchao Kou

Copyright (c) $2021 \mathrm{Ni}$ Zhang et al. This is an open access article distributed under the Creative Commons Attribution License, which permits unrestricted use, distribution, and reproduction in any medium, provided the original work is properly cited.

The replacement of coal gangue for aggregate in concrete can not only reduce the construction cost but also improve the environmental condition. The GFRP-coal gangue concrete-steel tubular (GGCS) columns provide a way to consume the coal gangue. The target of this work is to validate the feasibility of replacing ordinary concrete with coal gangue concrete and investigate the compression behavior of GGCS columns. The nonlinear analysis program of GGCS hollow columns under axial compression was proposed, and the axial compression tests of seven GGCS hollow columns were carried out. The program was verified through experimental results. On the basis of the correctness of the program, the influences of the typical parameters, such as the thickness of the glass fiber tube, the thickness of the steel tube, and the outer radius of the steel tube, on its axial compression performance were systematically analyzed. Finally, the analytical formula for predicting the axial bearing capacity of GGCS hollow column was proposed. The comparison of results indicated that the analytical results agreed well with the experimental results. The axial compression capacity of GGCS hollow columns increased linearly with the increase of the thickness of the glass fiber tube and the steel tube, but not linearly with the decrease of the outer radius of the steel tube. With the increase of the thickness of the glass fiber tube, the constraint effect of the glass fiber tube on gangue concrete was improved. With the increase of the thickness of the steel tube, the stiffness of GGCS hollow column increased. The conclusions of the presented work can provide references for the design and calculation of the GGCS columns.

\section{Introduction}

The coal gangue is called the resource in the wrong places. The annual output of coal gangue solid waste, which is produced during coal production, amounts to hundreds of millions of tons. The large amount of coal gangue in China has caused the environmental problems, and it is urgent to develop new directions to consume this huge amount of coal gangue. Many researchers have been devoted to explore the possible way to utilize the coal gangue in China [1-5]. Gao et al. [6] utilized coal gangue as a replacement of coarse aggregate in structural concrete and proposed a model for predicting the compressive strength of coal gangue concrete. $\mathrm{Li}$ and Wang [7] provided a comprehensive literature review of coal gangue utilization in building material production, energy generation, soil improvement, and other high-added applications. Xiao et al. [3] conducted experimental research to investigate the slump, setting time, air content, compressive strength, and splitting tensile strength of different mixture proportions of coal gangue concrete. Except the aggregate in concrete, the coal gangue has been utilized for the paste backfill material [8]. Concrete is the commonly used building material so far, and the aggregate is the main composite of concrete, which takes about $70-80 \%$ of the concrete volume. It is of great meaning if the coal gangue can be used for the substitution for the natural aggregate in concrete. It will be beneficial if the coal gangue can be utilized for members of buildings, such as beams or columns.

Fiber reinforced polymer (FRP) is one of the extensively used building materials because of its high corrosion resistance and low maintenance cost. It is common and effective to reinforce and upgrade existing structures with FRP composite materials including FRP sheets, FRP tubes, and 
FRP reinforcements. Various forms of FRP composite materials are developing rapidly $[9,10]$. FRP tubes can be used as permanent formworks for casting concrete to eliminate additional formworks and accelerate construction works [11]. Also, FRP tubes provide compressive constraints on concrete against compression, which effectively increase the carrying capacity and the ductility of composite members [12]. FRP-concrete-steel tubular columns are composed of the external FRP tube, the internal steel tube, and the sandwich concrete between both tubes. This new composite member has the advantages of high ductility, lightweight, resistant to corrosion, and full-use of building materials [13]. At present, many kinds of research studies have been carried out on FRP-concrete-steel tubular columns, including their compressive performance $[14,15]$, flexural performance $[16,17]$, and seismic performance $[18,19]$.

Glass fiber tube-gangue concrete-steel tube (GGCS) hollow column is a new type of the hollow column, which combines gangue concrete with GFRP-concrete-steel tube hollow column. The new hollow column is composed of the outer glass fiber tube, inner steel tube, and gangue concrete poured in double tubes, as shown in Figure 1. The new column can give full play to the advantages of the three materials because the glass fiber tube has excellent corrosion resistance [20]. The existence of the glass fiber tube can protect the inner steel tube and gangue concrete from corrosion. The elastic-plastic behavior of the steel tube is helpful to improve the ductility of the structure. The gangue concrete is in the three-way state of bearing capacity, and the bearing capacity is improved. Using coal gangue as concrete aggregate to prepare gangue concrete is in line with the green and sustainable development strategy and is the most environment friendly and economical way of resource utilization of coal gangue. It can not only make up for the shortage of natural sand but also solve the environmental pollution. Because of the above advantages, this new type of hollow column has a wide application prospect.

However, the mechanical properties of this new type of hollow column with gangue concrete have not been reported. Therefore, it is necessary to study the mechanics of the new hollow column. For the new hollow column, the most basic and ideal stress state is axial compression state. So, it is necessary to study the axial compression performance of this new type hollow columns. In the presented work, the nonlinear analysis program of GGCS hollow columns under axial compression force is compiled, and then, the axial compression tests of seven GGCS hollow columns are carried out. The load and longitudinal strain curves of GGCS hollow column computed by the program are compared with those measured in experiment to verify the correctness of the nonlinear analysis program. The influence of main parameters such as the wall thickness of the glass fiber tube and steel tube and the outer radius of the steel tube on its axial compression performance is analyzed systematically. Finally, the analytical formula of axial bearing capacity of GGCS hollow column is put forward, which can provide reference for the design and calculation of this new type hollow columns.

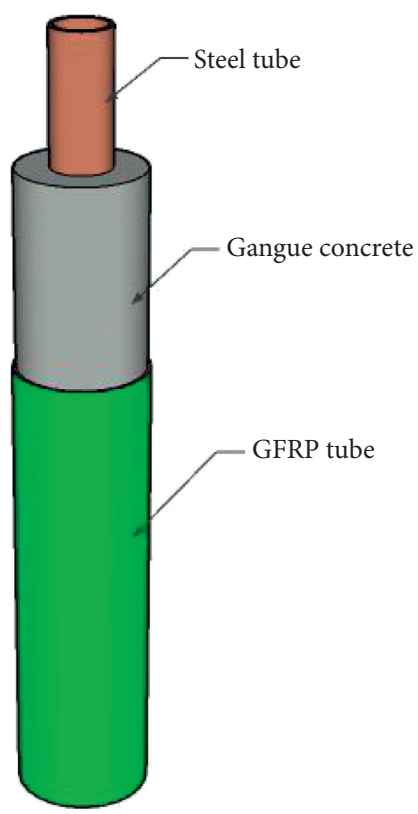

Figure 1: Glass fiber tube-gangue concrete-steel tube hollow column.

\section{Calculation and Analysis}

2.1. Basic Assumption and Constitutive Mode of Material. The nonlinear analysis program of GGCS hollow column under axial compression is compiled to calculate and analyze the influence of main parameters such as glass fiber tube wall thickness, steel tube wall thickness, and steel tube outer radius on its axial compression performance.

2.1.1. Basic Assumption. According to the mechanical characteristics of GGCS hollow column, the assumption is as follows:

(1) There is no relative slip between the glass fiber tube, steel tube, and gangue concrete

(2) During the loading process, the longitudinal deformation coordination and internal and external force balance are satisfied

$$
\begin{aligned}
& \varepsilon_{\mathrm{f}}=\varepsilon_{\mathrm{c}}=\varepsilon_{\mathrm{s}}, \\
& N=\sigma_{\mathrm{f}} A_{\mathrm{f}}+\sigma_{\mathrm{c}} A_{\mathrm{c}}+\sigma_{\mathrm{s}} A_{\mathrm{s}},
\end{aligned}
$$

where $\sigma_{\mathrm{f}}, \varepsilon_{\mathrm{f}}$, and $A_{\mathrm{f}}$ are the longitudinal stress, strain, and cross-sectional area of the glass fiber tube, respectively. The $\sigma_{\mathrm{c}}, \varepsilon_{\mathrm{c}}$, and $A_{\mathrm{c}}$ are the longitudinal stress, strain, and crosssectional area of the gangue concrete, respectively. $\sigma_{\mathrm{s}}, \varepsilon_{\mathrm{s}}$, and $A_{\mathrm{s}}$ are the longitudinal stress, strain, and cross-sectional area of the steel tube, respectively. $N$ is the axial load.

\subsubsection{Constitutive Model}

(1) Constitutive Model of the Concrete. In 1998, Samaan et al. [21] proposed the stress-strain relationship of the concrete 
confined by fiber reinforced composites which can be expressed as follows:

$$
\begin{aligned}
& f_{\mathrm{c}}=\frac{\left(E_{1}-E_{2}\right) \varepsilon_{\mathrm{c}}}{\left\{1+\left[\left(\left(E_{1}-E_{2}\right) \varepsilon_{\mathrm{c}}\right) / f_{\mathrm{o}}\right]^{1.5}\right\}^{(1 / 1.5)}}+E_{2} \varepsilon_{\mathrm{c}}, \\
& E_{1}=3950 \sqrt{f_{\mathrm{c}}^{\prime}} \\
& E_{2}=245.61 f_{\mathrm{c}}^{\prime} 0.2+1.3456 \frac{E_{\mathrm{f}} t_{\mathrm{f}}}{D}, \\
& f_{\mathrm{o}}=0.872 f_{\mathrm{c}}^{\prime}+0.371 f_{\mathrm{r}}+6.258, \\
& f_{\mathrm{r}}=\frac{2 f_{\mathrm{f}} t_{\mathrm{f}}}{D}
\end{aligned}
$$

where $f_{\mathrm{c}}$ and $\varepsilon_{\mathrm{c}}$ are the longitudinal stress and strain of the concrete, respectively. $E_{1}$ and $E_{2}$ are the slope of the first and second sections of the curve, respectively. $f_{0}$ is the plastic stress at the turning point of the second curve. $f_{\mathrm{c}}^{\prime}$ is the peak stress of the unconfined concrete. $f_{\mathrm{r}}$ is the lateral restraint on the concrete. $f_{\mathrm{f}}, E_{\mathrm{f}}$, and $t_{\mathrm{f}}$ are the circumferential strength, circumferential modulus of elasticity, and the wall thickness of the fiber tubes, respectively. $D$ is the diameter of the concrete.

(2) Constitutive Model of the Glass Fiber Tube. The stressstrain relationship of glass fiber proposed by Lu et al. [22] in 2006 was as follows:

$$
\sigma_{\mathrm{f}}=E_{\mathrm{fz}} \varepsilon_{\mathrm{f}}\left[1-\frac{\left(v_{\mathrm{c}}-v_{\mathrm{fz}}\right) v_{\mathrm{fh}}}{\left(\left(\left(1-v_{\mathrm{c}}-2 v_{\mathrm{c}}^{2}\right) E_{\mathrm{fh}} t\right) / E_{\mathrm{c}} R\right)+\left(1-v_{\mathrm{fz}} v_{\mathrm{fh}}\right)}\right],
$$

where $\sigma_{\mathrm{f}}$ and $\varepsilon_{\mathrm{f}}$ are the longitudinal stress and strain of the glass fiber tube, respectively. $E_{\mathrm{fh}}$ and $E_{\mathrm{fz}}$ are the circumferential and longitudinal elastic modulus of the glass fiber tube, respectively. $v_{\mathrm{fh}}$ and $v_{\mathrm{fz}}$ are the circumferential and longitudinal Poisson's ratio of the glass fiber tube, respectively. $v_{c}$ is Poisson's ratio of the concrete. $R$ is the concrete radius. $t$ is the wall thickness of the glass fiber tube.

(3) Constitutive Model of the Steel Tube. The stress-strain curve of the steel tube adopts the model proposed by Zhong [23] in 1994, which is composed of elastic phase and strengthening phase, as shown in Figure 2.

The expressions of stress and strain are as follows:

$$
\sigma_{\mathrm{s}}= \begin{cases}E_{\mathrm{t}} \varepsilon_{\mathrm{s}}, & \left(\varepsilon_{\mathrm{s}} \leq \varepsilon_{\mathrm{ty}}\right), \\ f_{\mathrm{ty}}+0.01 E_{\mathrm{t}}\left(\varepsilon_{\mathrm{s}}-\varepsilon_{\mathrm{ty}}\right), & \left(\varepsilon_{\mathrm{s}}>\varepsilon_{\mathrm{ty}}\right),\end{cases}
$$

where $\sigma_{\mathrm{s}}$ and $\varepsilon_{\mathrm{s}}$ are the stress and strain of the steel tube, respectively. $f_{\mathrm{ty}}$ is the yield strength of the steel tube. $E_{\mathrm{t}}$ is the elastic modulus of the steel tube.

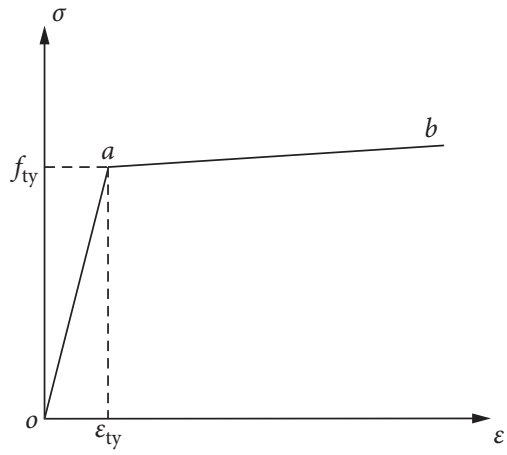

FIGURE 2: Steel tube stress-strain relationship.

\subsection{Computational Procedure}

(1) Input the material characteristics, geometric dimensions, and other parameters of GGCS hollow column, that is, the elastic modulus of the glass fiber tube, gangue concrete, steel tube, gangue concrete section area, glass fiber tube, steel tube diameter, and wall thickness

(2) Assuming the longitudinal initial strain value, the corresponding stress is calculated according to the stress-strain constitutive relation of the glass fiber tube, steel tube, and gangue concrete

(3) According to the equilibrium condition of the force, the longitudinal load $N$ is calculated

(4) The whole process curve of axial compression loadlongitudinal strain of GGCS hollow column can be obtained by increasing the longitudinal strain step by step. The calculation steps are shown in Figure 3.

\section{Experimental Procedure}

3.1. Specimen Design. In order to validate the reliability of the proposed nonlinear program for axial compression of GGCS hollow column, seven axial compression members of GGCS hollow column are made, and the section form of specimens is shown in Figure 4.

The glass fiber tube manufactured by Shenyang Tianyang Group Co., Ltd. is utilized. The wall thickness of the glass fiber tube is $5 \mathrm{~mm}$, the inner diameter is $200 \mathrm{~mm}$, the length is $700 \mathrm{~mm}$, and the winding angle of fiber is $80^{\circ}$. The main test parameters are given in Table 1 . The parameters of GGCS1, GGCS2, and GGCS3 are the same. GGCS1 is placed upright, GGCS2 is upside down, and the end of GGCS3 is strengthened with CFRP sheet. The influence of placement mode of specimen and end reinforcement on bearing capacity is studied.

The coal gangue used in the specimen is taken from Haizhou mining area in Fuxin, Liaoning Province. After crushing, screening, cleaning, drying, and a series of 


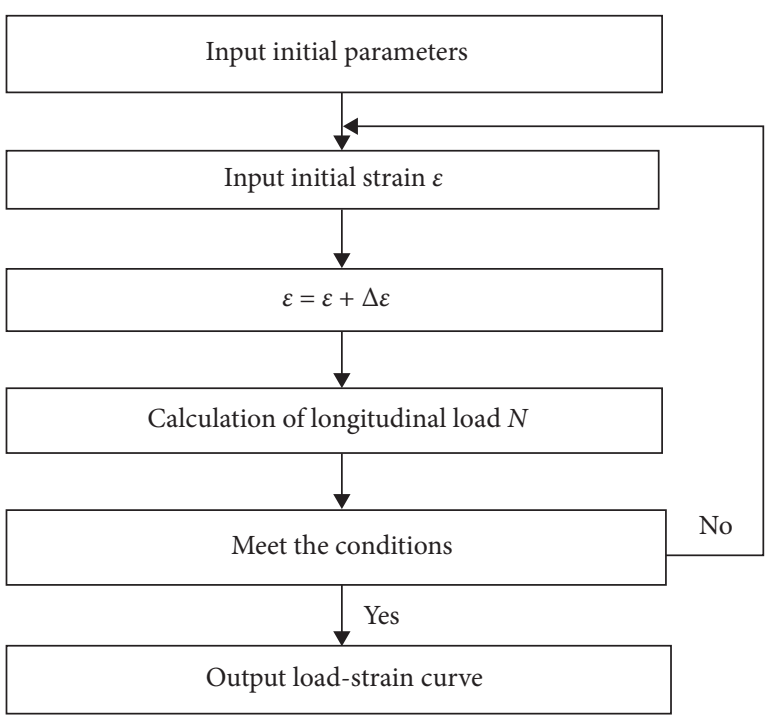

FIgURE 3: Sketch of calculation.

treatment, the coarse aggregate of coal gangue is obtained by screening, as shown in Figure 5. Its gradation meets the requirements of $5-20 \mathrm{~mm}$ continuous gradation. The main chemical composition and basic physical properties of coal gangue are given in Tables 2 and 3 . The fine aggregate is natural river sand, the cement is 42.5 grade Daying ordinary Portland cement, the fly ash is grade II fly ash, the test water is tap water, the water reducer is a polycarboxylate superplasticizer, the dosage is $1.5 \%-2.5 \%$, and the water reduction rate is $20 \%-30 \%$. The mix proportion of coal gangue concrete is given in Table 4 .

3.2. Specimen Preparation. First, the glass fiber tube and steel tube are made according to the design size, and then, the steel tube and glass fiber tube are fixed on the board with black mortar to ensure that the inner steel tube is in the middle. Then, the gangue concrete is poured between the glass fiber tube and the steel pipe and vibrated tightly. While pouring gangue concrete, the gangue concrete cube block with side length equaling $150 \mathrm{~mm}$ is made. After 28 days, the compressive strength of gangue concrete cube is $35.8 \mathrm{MPa}$. The manufacturing process of specimens is shown in Figure 6.

3.3. Test Phenomena and Failure Modes. The failure modes of the specimens are almost the same. This study takes GGCS1 column as an example to illustrate the phenomenon and failure mode of GGCS column under axial compression force. At the initial stage of loading, the surface of GGCS1 has no obvious change. When the load reaches about $70 \% \mathrm{Pu}$ ( $\mathrm{Pu}$ indicates the ultimate load), the white stripes begin to appear on the surface of GFRP tube, accompanied by slight fiber tearing sound. As the load continues to increase, the white stripes gradually increase. The color of fiber layer of GFRP changed from uniform light green to irregular local white. With the increase of load, the fiber fracture increases and the range of white stripes expands. When the load is close to $\mathrm{Pu}$, fiber fracture and resin cracking occur frequently. When the load reaches the ultimate load $\mathrm{Pu}$, the fiber breaks at a distance of $180-320 \mathrm{~mm}$ from the top, accompanied by a loud noise, and peels from the fracture along the fiber direction to both sides. The core gangue concrete is crushed. The steel tube is basically in good condition without obvious buckling phenomenon and only protrudes inward in some parts. The failure mode of specimen GGCS1 is shown in Figure 7.

3.4. Model Validation. The load-longitudinal strain curve calculated by using the program of nonlinear analysis is compared with the curve obtained by the experiment, as shown in Figure 7 . With the increase of load, the load and longitudinal strain curves mainly show three stages: the initial straight section, the elastic-plastic microbending section, and the strengthening straight section. At the initial stage of loading, the specimen is in the elastic working stage, in which the transverse deformation of gangue concrete is small. So, the interaction between the gangue concrete and glass fiber tube is not obvious. The curve shows a linear growth at this stage. When the load reaches $29 \%$ of the ultimate load, the restraint effect of the glass fiber tube on gangue concrete appears. The load does not show linear growth along with strain. At this time, the growth rate of longitudinal strain is faster than that of the load. In this stage, the transverse deformation of gangue concrete increases rapidly, which results in the radial pressure between the glass fiber tube and gangue concrete. The glass fiber tube can restrain the gangue concrete. When the load continues to $61 \%$ of the ultimate load, the curve changes linearly. It can be seen from Figure 8 that the calculated curves are in good agreement with the experimental curves. It shows that it is feasible to analyze the axial compression performance of GGCS hollow columns by using the proposed nonlinear analysis program.

\section{Influence of Design Parameters}

Based on the validation of the proposed program, the main parameters affecting the axial compression performance of GGCS hollow columns are analyzed. The basic parameters used in the program are as follows: the thickness and inner diameter of the glass fiber tube, the thickness and outer radius of the steel tube, and strength grade of gangue concrete are $5 \mathrm{~mm}, 200 \mathrm{~mm}, 4 \mathrm{~mm}, 45 \mathrm{~mm}$, and C30, respectively. The influences of the above parameters on the load-longitudinal strain curve of GGCS hollow column is studied by changing the thickness of the glass fiber tube, the wall thickness of the steel tube, and the outer radius (hollow ratio) of the steel tube. When one parameter is adjusted, the other basic parameters kept unchanged.

4.1. Influence of the Thickness of the Glass Fiber Tube. The load-longitudinal strain curves of GGCS hollow columns with different glass fiber tube thicknesses are shown in Figure 9. The glass fiber tube thickness is set to be $3,4,5,6$, and $7 \mathrm{~mm}$, and the other conditions are the same. It can be 


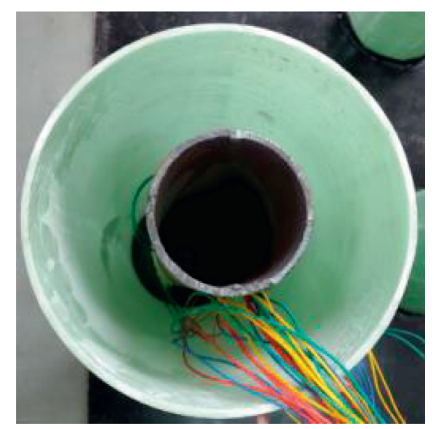

(a)

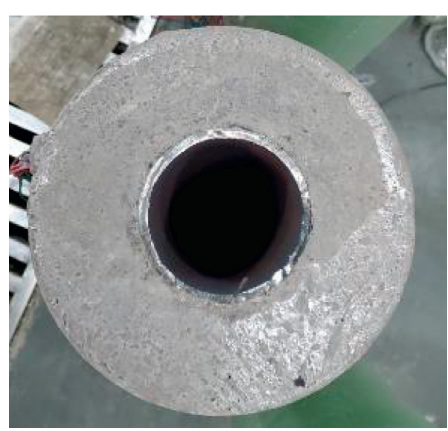

(b)

Figure 4: Section form of the specimen.

TABLE 1: Chart of experimental parameters and results.

\begin{tabular}{|c|c|c|c|c|}
\hline \multirow{2}{*}{ Specimens } & \multirow{2}{*}{ Wall thickness of glass fiber tube (mm) } & \multicolumn{2}{|c|}{ Steel tube } & \multirow{2}{*}{ Ultimate load $(\mathrm{kN})$} \\
\hline & & External diameter (mm) & Wall thickness (mm) & \\
\hline GGCS1 & 5 & 89 & 4 & 2021 \\
\hline GGCS2 & 5 & 89 & 4 & 1917 \\
\hline GGCS3 & 5 & 89 & 4 & 2064 \\
\hline GGCS4 & 3 & 89 & 4 & 1430 \\
\hline GGCS5 & 5 & 89 & 6 & 2111 \\
\hline GGCS6 & 5 & 108 & 4 & 1818 \\
\hline GGCS7 & 5 & 60 & 4 & 2297 \\
\hline
\end{tabular}

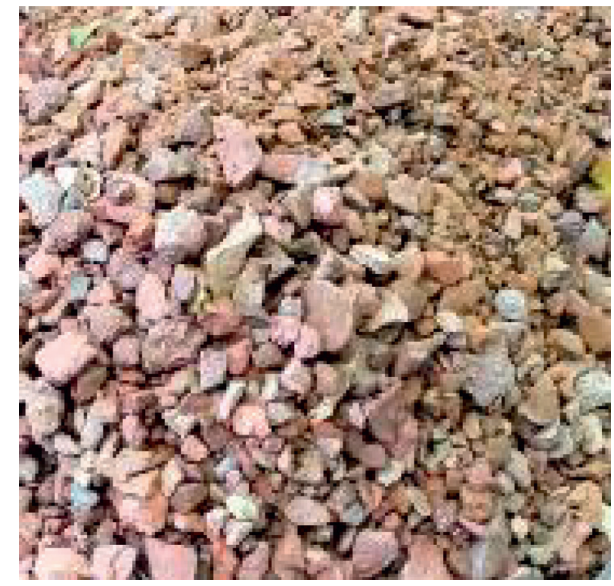

Figure 5: Coal gangue coarse aggregate.

TABLE 2: Main chemical composition of coal gangue.

\begin{tabular}{lccccccc}
\hline $\begin{array}{l}\text { Chemical } \\
\text { composition }\end{array}$ & $\mathrm{SiO}_{2}$ & $\mathrm{Al}_{2} \mathrm{O}_{3}$ & $\mathrm{Fe}_{2} \mathrm{O}_{3}$ & $\mathrm{CaO}$ & $\mathrm{MgO}$ & $\mathrm{K}_{2} \mathrm{O}$ & $\mathrm{SO}_{3}$ \\
\hline Content \% & 55.57 & 21.00 & 6.57 & 3.65 & 2.50 & 4.10 & 3.32 \\
\hline
\end{tabular}

seen from Figure 8 that at the initial stage of loading, the curves are basically the same. When the load reaches $28 \%-$ $40 \%$ ultimate load (glass fiber tube wall thickness $3 \mathrm{~mm}$ : $40.3 \%$; $4 \mathrm{~mm}$ : 36.2\%; $5 \mathrm{~mm}$ : 32.8\%; $6 \mathrm{~mm}: 30.0 \%$; $7 \mathrm{~mm}$ : $27.6 \%)$, the change of the glass fiber tube has an impact on the curve. The slope of the load-longitudinal strain curve of the member with large wall thickness is larger than that of the member with small wall thickness. At the same longitudinal strain value, the load value of the member with large wall thickness is higher than that of the member with small wall thickness. The ultimate load of the members with $4,5,6$, and $7 \mathrm{~mm}$ wall thickness of the glass fiber tube is $14.1 \%, 28.4 \%, 42.7 \%$, and $57.2 \%$ higher than that of the members with $3 \mathrm{~mm}$ wall thickness. The wall thickness of the glass fiber tube has little effect on the initial stiffness of GGCS column. With the increase of the wall thickness of the glass fiber tube, the restraint effect on gangue concrete is improved. The reason is that the fracture of the glass fiber tube needs more lateral force, so the load of GGCS hollow column increases.

Figure 10 compares and analyzes the variation law of ultimate load of GGCS hollow column with glass fiber tube wall thickness under different steel tube wall thicknesses and steel tube outer radii. It can be seen from Figure 10 that the influence law of the change of glass fiber tube wall thickness on the ultimate load of GGCS hollow column is roughly the same, that is, the ultimate load increases with the increase of glass fiber tube wall thickness, which is approximately linear. Figure 10(a) shows the variation of ultimate load of GGCS hollow column with glass fiber tube wall thickness under different steel tube wall thicknesses. The values of steel tube wall thickness range from $3 \mathrm{~mm}$ to $7 \mathrm{~mm}$, and the slope of the curve is roughly the same. It shows that the change of steel tube wall thickness has a similar effect on the ultimate load of GGCS hollow column. For members with the same steel tube thickness, the ultimate load of GGCS hollow column increases about $228 \mathrm{kN}$ when the glass fiber tube thickness increases by $1 \mathrm{~mm}$. Figure 10(b) shows the variation of ultimate load of GGCS hollow column with the wall thickness of the glass fiber tube under different outer radii of 
TABLE 3: Basic physical properties of coal gangue.

\begin{tabular}{lcccc}
\hline Coarse aggregate & Apparent density $\left(\mathrm{kg} / \mathrm{m}^{3}\right)$ & Bulk density $\left(\mathrm{kg} / \mathrm{m}^{3}\right)$ & Water absorption $(\%)$ & Crushing value $(\%)$ \\
\hline Coal gangue & 2606 & 1235 & 7.4 & 17.1 \\
\hline
\end{tabular}

TABle 4: Coal gangue concrete mix proportion $\left(\mathrm{kg} / \mathrm{m}^{3}\right)$.

\begin{tabular}{cccccccc}
\hline & Cement & Water & Coal gangue & Stone & Sand & Water reducing agent & Fly ash \\
\hline Gangue concrete & 320 & 175 & 820 & - & 924 & 6.6 & 80 \\
\hline
\end{tabular}

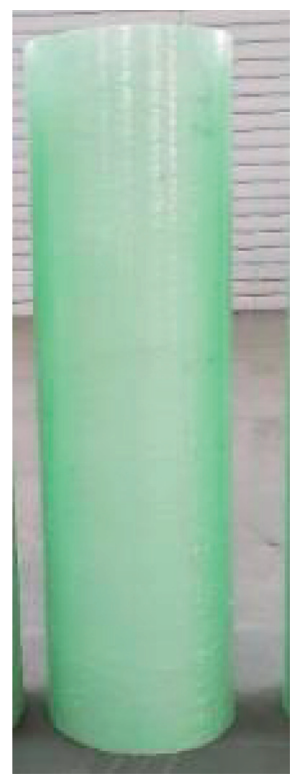

(a)

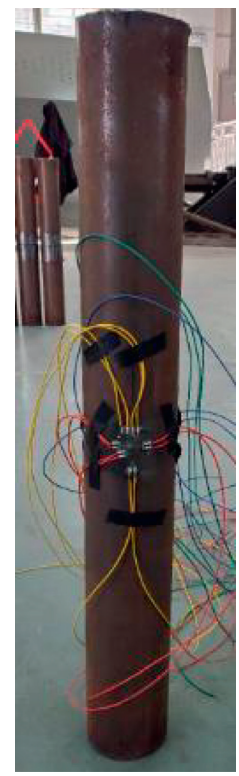

(b)

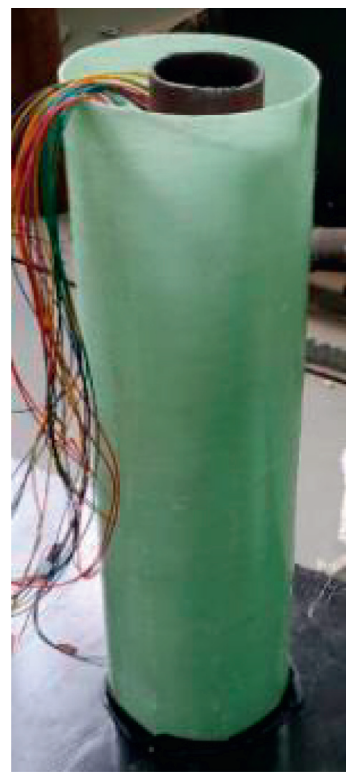

(c)

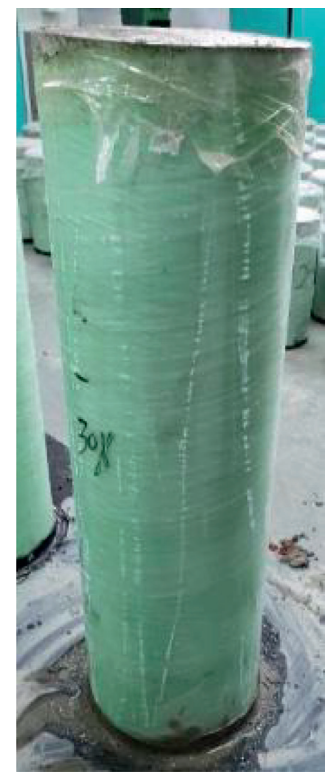

(d)

Figure 6: Component production process. (a) Glass fiber tube. (b) Steel tube. (c) Parts assembly. (d) Finished specimens.

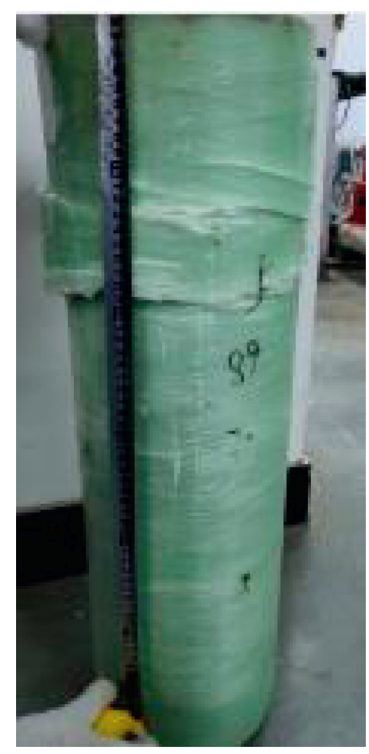

(a)

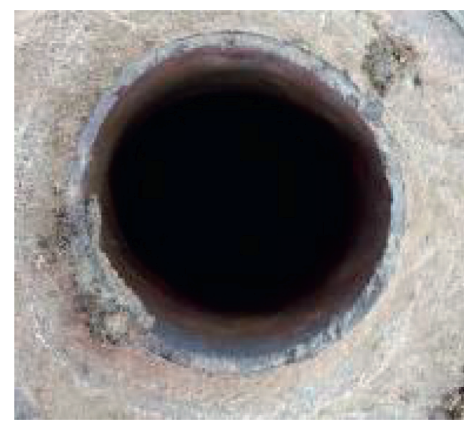

(b)

Figure 7: Failure mode of specimen GGCS1. (a) GFRP tube. (b) Steel tube. 

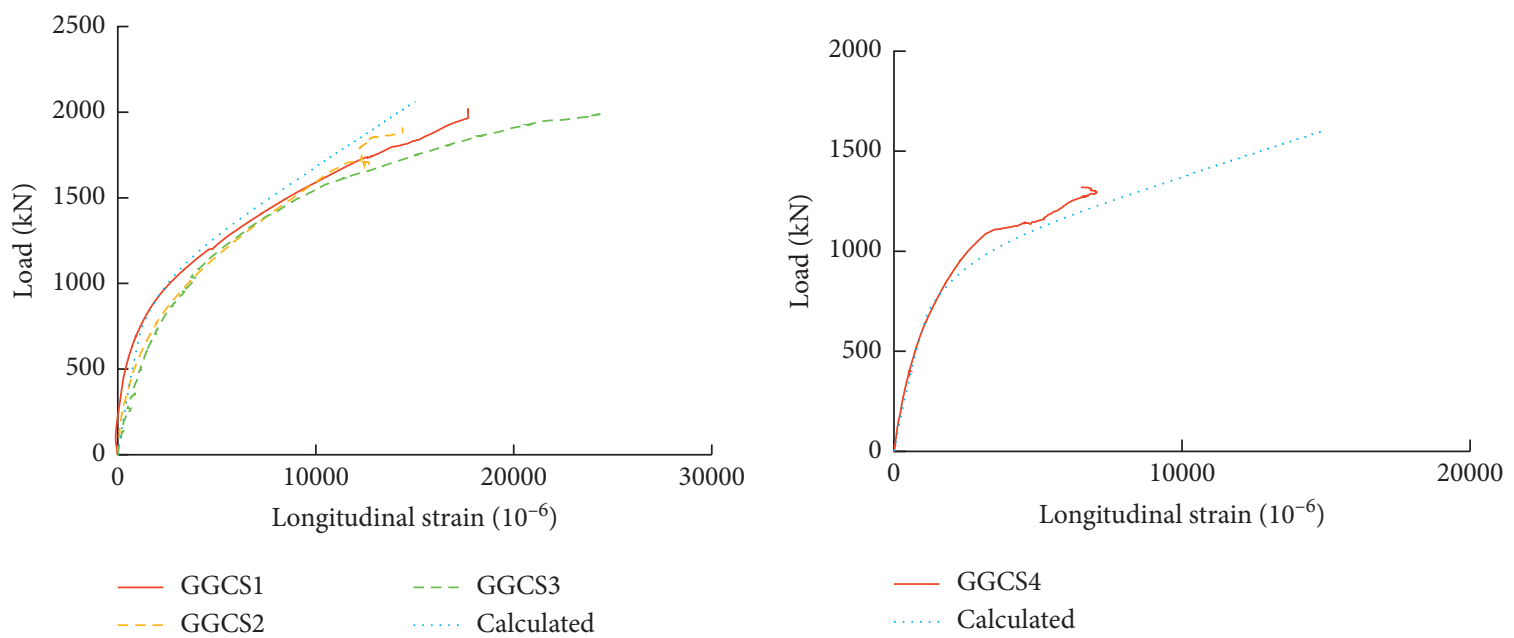

(a)

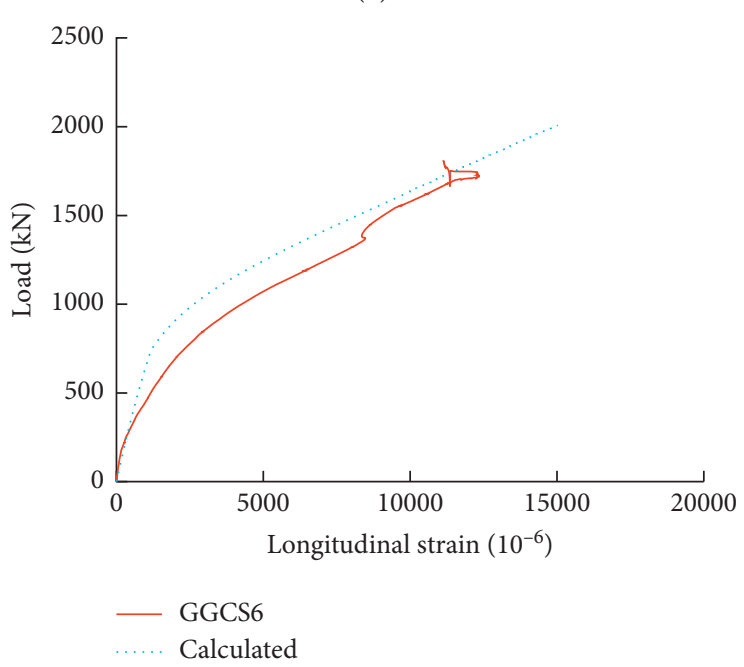

(c)

(d)

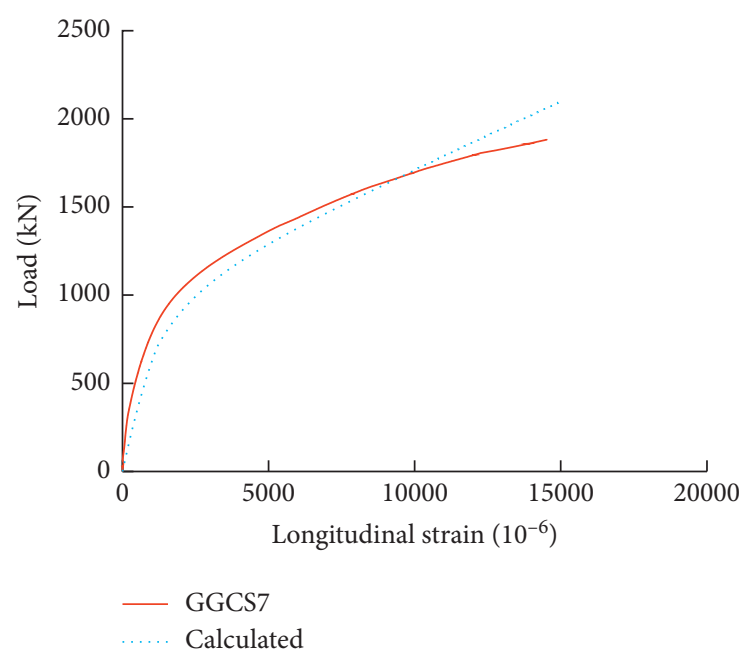

(e)

FIGURE 8: Comparison between calculation and test curves. (a) GGCS1, GGCS2, and GGCS3. (b) GGCS4. (c) GGCS5. (d) GGCS6. (e) GGCS7. 


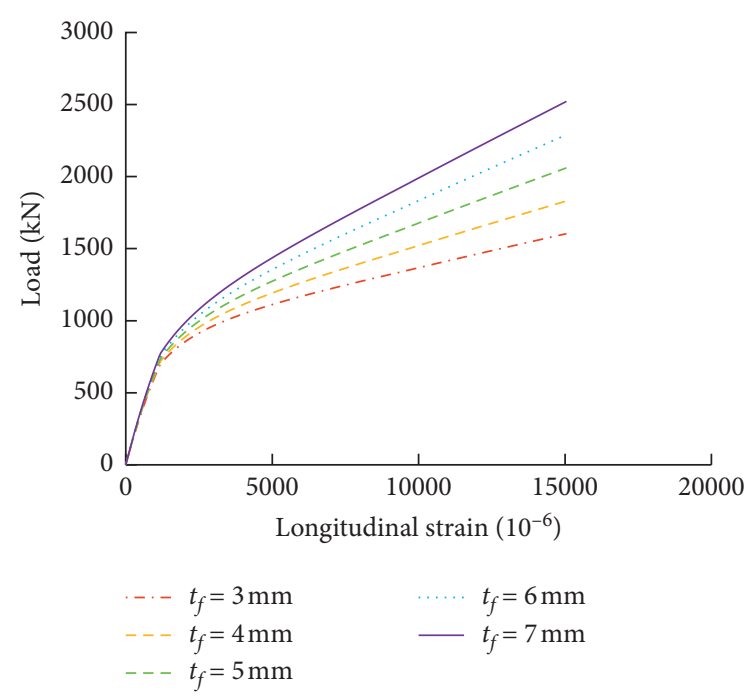

Figure 9: Effect of thickness of glass fiber tubes.

the steel tube. When the outer radius of the steel tube is from $35 \mathrm{~mm}$ to $75 \mathrm{~mm}$, the slope of the curve decreases with the increase of the outer radius of the steel tube. The results show that with the increase of the outer radius of the steel tube, the influence of the wall thickness of the glass fiber tube on the ultimate load gradually decreases. When the outer radius of the steel tube is $35,45,55,65$, and $75 \mathrm{~mm}$, the ultimate load of GGCS hollow column increases 235, 227, 220, 211, and $202 \mathrm{kN}$ with the increase of $1 \mathrm{~mm}$ of the wall thickness of the glass fiber tube.

4.2. Influence of Steel Tube Wall Thickness. When the steel tube wall thickness is $3,4,5,6$, and $7 \mathrm{~mm}$ respectively, and other conditions are the same, the load-longitudinal strain curves of GGCS hollow columns with different steel tube wall thicknesses are shown in Figure 11. It can be seen from Figure 10 that the initial slope of the curve of the member with large wall thickness is greater than that of the member with small wall thickness. It shows that the steel tube wall thickness has an effect on the stiffness of the component, and the stiffness of the component increases with the increase of the steel tube wall thickness. At the same longitudinal strain, the load value of the member with large wall thickness is higher than that of the member with small wall thickness. The ultimate bearing capacity of members with $4,5,6$, and $7 \mathrm{~mm}$ steel tube wall thickness is $3.2 \%, 6.4 \%, 9.4 \%$, and $12.4 \%$ higher than that of members with $3 \mathrm{~mm}$ steel tube wall thickness. The reason is that the longitudinal section area of the steel tube increases with the increase of steel tube wall thickness. Therefore, the bearing capacity of the steel tube is improved. So the load of GGCS hollow column is increased.

Figure 12 compares and analyzes the variation law of ultimate load of GGCS hollow column with steel tube wall thickness under different glass fiber tube wall thicknesses and steel tube outer radii. It can be seen from Figure 12 that the influence law of the change of steel tube wall thickness on the ultimate load of GGCS hollow column is roughly the same. That is to say, the ultimate load increases linearly with the increase of steel tube wall thickness. Figure 12(a) shows the variation law of ultimate load of GGCS hollow column with steel tube wall thickness under different glass fiber tube wall thicknesses. The wall thickness of the glass fiber tube ranges from $3 \mathrm{~mm}$ to $7 \mathrm{~mm}$, and the slope of the curve is approximately the same. For members with the same glass fiber tube wall thickness, the ultimate load of GGCS hollow column increases about $61 \mathrm{kN}$ with the increase of $1 \mathrm{~mm}$ of steel tube wall thickness. Figure 12(b) shows the variation of ultimate load of GGCS hollow column with the wall thickness of the steel tube under different outer radii of the steel tube. When the outer radius of the steel tube is from $35 \mathrm{~mm}$ to $75 \mathrm{~mm}$, the slope of the curve increases with the increase of the outer radius of the steel tube. It shows that with the increase of outer radius of the steel tube, the influence of steel tube wall thickness on ultimate load increases gradually. This is because with the increase of the outer radius of the steel tube, the longitudinal section area of the steel tube increases, so the bearing capacity of the steel tube increases. However, as the outer radius of the steel tube increases, the longitudinal section area of gangue concrete decreases, and the combination of the steel tube and gangue concrete leads to the reduction of ultimate load of GGCS hollow column. When the outer radius of the steel tube is 35 , $45,55,65$, and $75 \mathrm{~mm}$, the ultimate load of GGCS hollow column increases by $47,62,77,93$, and $108 \mathrm{kN}$ with the increase of $1 \mathrm{~mm}$ of steel tube thickness.

\subsection{Influence of the Outer Radius of Steel Tubes (Hollow Ratio).} The outer radius of the steel tube is set to be $35,45,55,65$, and $75 \mathrm{~mm}$ to investigate the influence of outer radius of the steel tube on compression capacity. The load-longitudinal strain curves of GGCS hollow column corresponding to different outer radii of the steel tube are shown in Figure 13. It can be seen from Figure 13 that in the initial stage of load action, the curves are basically the same. When the load reaches $34 \%-38 \%$ of the ultimate load (the outer radius of the steel tube $35 \mathrm{~mm}$ : $33.7 \%$; $45 \mathrm{~mm}$ : $34.1 \%$; $55 \mathrm{~mm}$ : 34.9\%; $65 \mathrm{~mm}: 36.1 \%$; $75 \mathrm{~mm}: 37.9 \%$ ), the change of outer radius of the steel tube has an impact on the curve. The slope of load-longitudinal strain curve of the member with small outer radius of the steel tube is larger than that of the member with large outer radius of the steel tube. At the same longitudinal strain value, the load value of the member with small outer radius of the steel tube is higher than that of the member with large outer radius of the steel tube. The ultimate bearing capacity of members with outer radius of $35,45,55$, and $65 \mathrm{~mm}$ is $15.1 \%, 13.3 \%, 10.2 \%$, and $5.8 \%$ higher than that of members with outer radius of $75 \mathrm{~mm}$. With the increase of outer radius of the steel tube, the cross-sectional area of gangue concrete decreases gradually. Moreover, the restraint effect of the steel tube on gangue concrete will be weakened, which will reduce the ultimate load of GGCS hollow column.

The variation of the ultimate load of GGCS hollow column along with outer radius of the steel tube is shown in Figure 14. The thickness of steel tubes and glass fiber tubes is changed from $3 \mathrm{~mm}$ to $7 \mathrm{~mm}$ with a step equaling to 


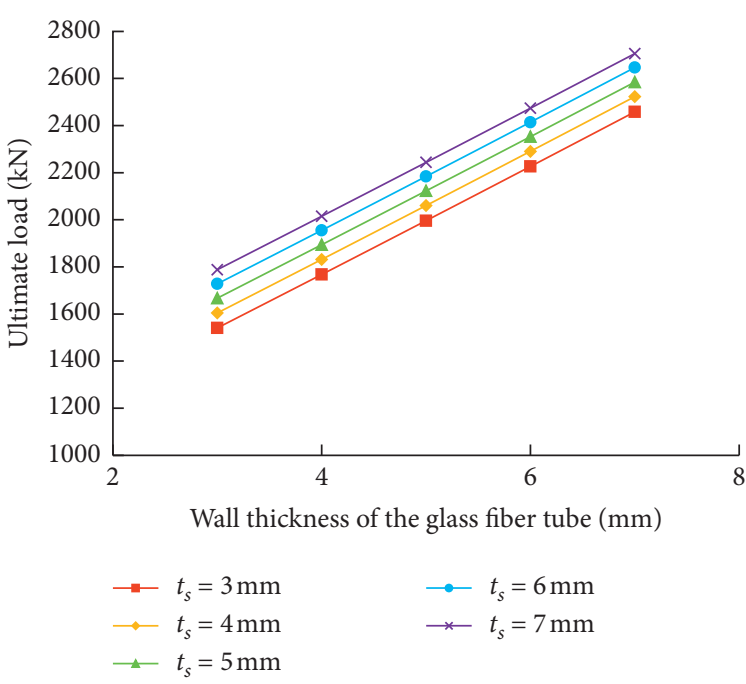

(a)

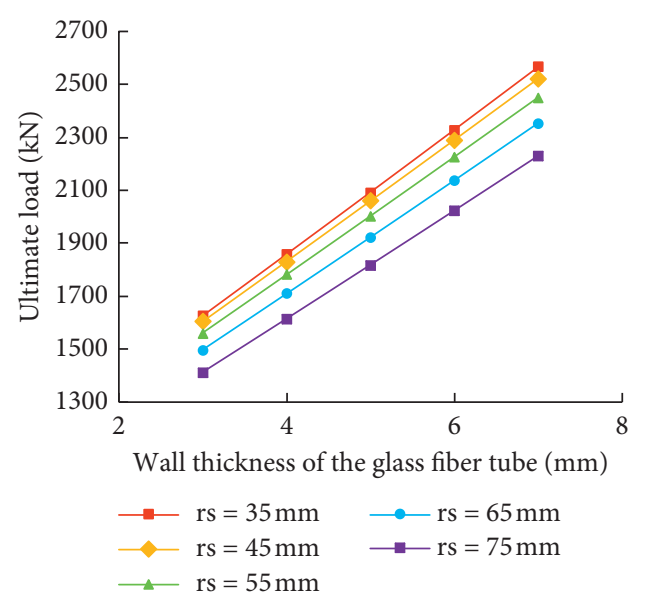

(b)

FIGURE 10: Influence of thickness of the glass fiber tube on ultimate load.

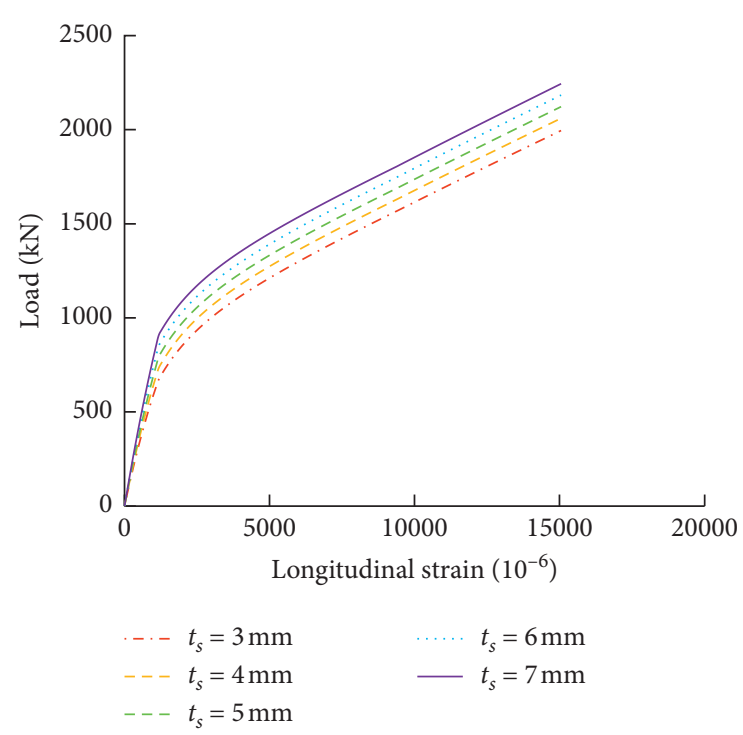

FIGURE 11: Effect of thickness of steel tubes.

$1 \mathrm{~mm}$. It can be seen from Figure 14 that the influence law of the change of steel tube thickness on the ultimate load of GGCS hollow column is roughly the same. That is to say, the ultimate load decreases with the increase of outer radius of the steel tube, but it does not change linearly. Figure 14(a) shows the variation of ultimate load of GGCS hollow column with outer radius of the steel tube under different thicknesses of the glass fiber tube. The thickness of the glass fiber tube ranges from $3 \mathrm{~mm}$ to $7 \mathrm{~mm}$, and the curve change is almost the same. It shows that the influence of the outer radius of the steel tube on the ultimate load of GGCS hollow column is similar, but not linear. Figure 14(b) shows the variation of ultimate load of GGCS hollow column along with outer radius of the steel tube owing different steel tube thicknesses. When the thickness of the steel tube is changed from $3 \mathrm{~mm}$ to $7 \mathrm{~mm}$, the influence of the change of the outer radius of the steel tube on the ultimate load increases gradually. The reason is that the restraint effect of the steel tube with small thickness on gangue concrete is weaker than that of the steel tube with large thickness. When the outer radius of the steel tube increases, the restraint effect of the steel tube on gangue concrete decreases. Therefore, the ultimate load of members with small steel tube thickness is more affected by the outer radius of the steel tube than that of members with large steel tube thickness. When the steel tube thickness is $3,4,5,6$, and $7 \mathrm{~mm}$, respectively, the outer radius of the steel tube increases from $35 \mathrm{~mm}$ to $75 \mathrm{~mm}$, and the ultimate load of GGCS hollow column decreases by $16.4 \%, 13.1 \%$, $9.9 \%, 6.9 \%$, and $4.0 \%$, respectively.

\section{Bearing Capacity of GGCS Hollow Column under Axial Compression}

According to the mechanical characteristics of GGCS hollow column, the ultimate equilibrium method is used to establish the calculation formula of axial bearing capacity of GGCS hollow column.

5.1. Limit Equilibrium Method. The following assumptions are made: (1) the deformations between the glass fiber tube and gangue concrete, gangue concrete, and steel tube are coordinated without relative slip. (2) The glass fiber tube and steel tube belong to thin-walled structure, and the radial stress of the glass fiber tube and steel tube is far less than the circumferential stress in the limit state. So, the radial stress is ignored. (3) The circumferential stress of the glass fiber tube and steel tube is evenly distributed along the tube wall.

The stress analysis of GGCS hollow column is shown in Figure 15.

From the equilibrium condition of the force, it is concluded that 


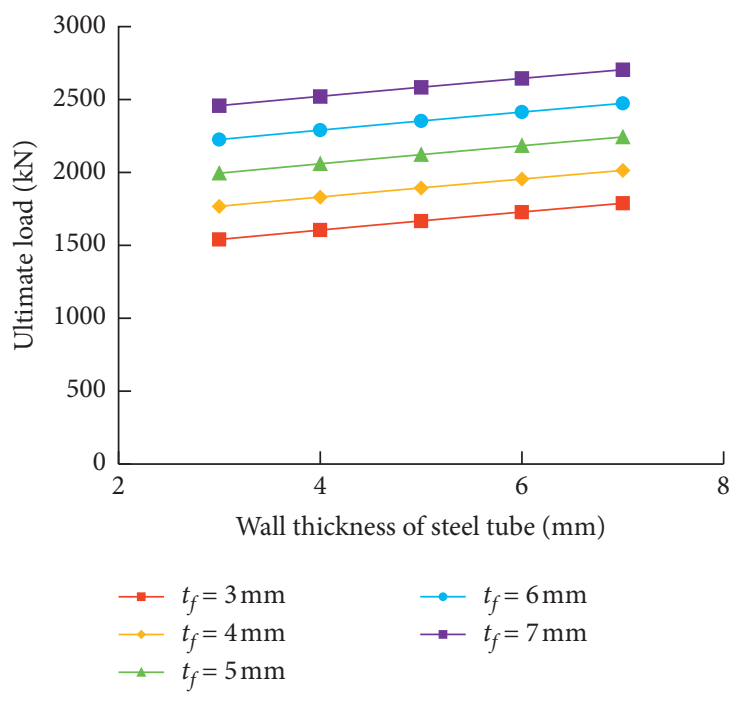

(a)

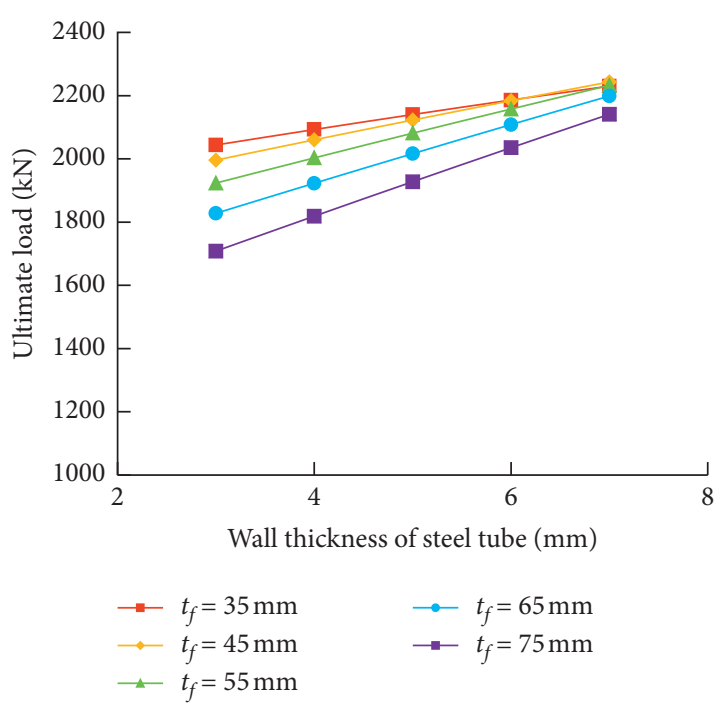

(b)

FIGURE 12: Influence of wall thickness of the steel tube on ultimate load.

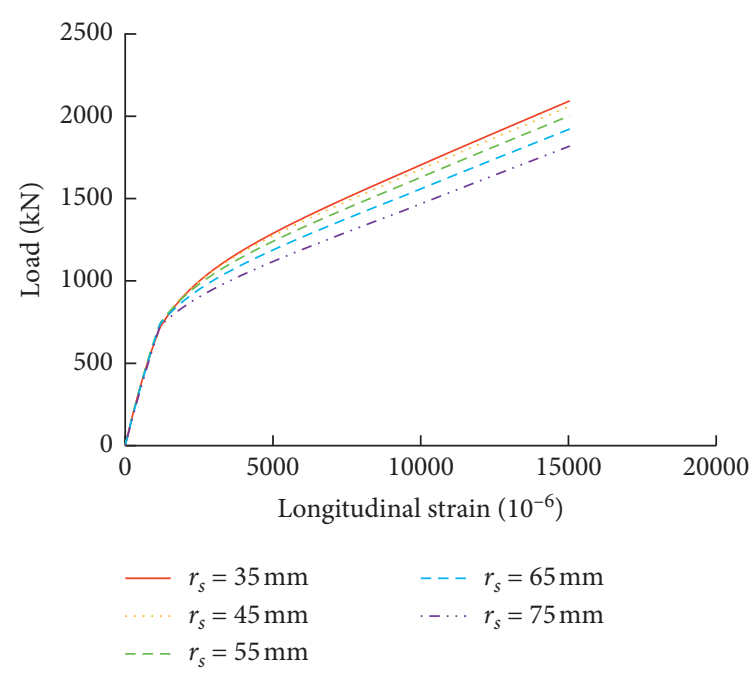

FIGURE 13: Effect of outer radius of the steel tube.

$$
\begin{aligned}
N & =A_{\mathrm{f}} \sigma_{\mathrm{f} 2}+A_{\mathrm{c}} \sigma_{\mathrm{c}}+A_{\mathrm{s}} \sigma_{\mathrm{s} 2}, \\
2 \sigma_{\mathrm{f} 1} t_{\mathrm{f}} & =p_{\mathrm{f}} \cdot 2 r_{\mathrm{f}}, \\
2 \sigma_{\mathrm{s} 1} t_{\mathrm{s}} & =p_{\mathrm{s}} \cdot 2 r_{\mathrm{s}},
\end{aligned}
$$

where $A_{\mathrm{f}}, \sigma_{\mathrm{f} 2}, \sigma_{\mathrm{f} 1}, t_{\mathrm{f}}, r_{\mathrm{f}}$, and $p_{\mathrm{f}}$ are the cross-sectional area, longitudinal stress, circumferential stress, wall thickness, outer radius, and binding force of the glass fiber tube, respectively. $A_{\mathrm{c}}$ and $\sigma_{\mathrm{c}}$ are the cross-sectional area and longitudinal stress of the concrete, respectively. $A_{\mathrm{s}}, \sigma_{\mathrm{s} 2}, \sigma_{\mathrm{s} 1}, t_{\mathrm{s}}$, $r_{s}$, and $p_{s}$ are the cross-sectional area, longitudinal stress, circumferential stress, wall thickness, outer radius, and binding force of the steel tube.
The values of $p_{\mathrm{f}}$ and $p_{\mathrm{s}}$ were obtained according to results presented in [24].

$$
\begin{aligned}
& p_{\mathrm{f}}=\frac{k_{4} m_{1} \varepsilon_{\mathrm{c}}+\left(k_{5} m_{1}+k_{3} m_{2}\right) \varepsilon_{\mathrm{c}}^{2}}{k_{1} k_{4}+\left(k_{2} k_{5}-k_{3} k_{6}\right) \varepsilon_{\mathrm{c}}^{2}+\left(k_{1} k_{5}+k_{2} k_{4}\right) \varepsilon_{\mathrm{c}}}, \\
& p_{\mathrm{s}}=\frac{k_{1} m_{2} \varepsilon_{\mathrm{c}}+\left(k_{6} m_{1}+k_{2} m_{2}\right) \varepsilon_{\mathrm{c}}^{2}}{k_{1} k_{4}+\left(k_{2} k_{5}-k_{3} k_{6}\right) \varepsilon_{\mathrm{c}}^{2}+\left(k_{1} k_{5}+k_{2} k_{4}\right) \varepsilon_{\mathrm{c}}}, \\
& k_{1}=\frac{\left(1-v_{\mathrm{h}}^{2}\right) r_{\mathrm{c}}\left(r_{\mathrm{f}}+r_{\mathrm{c}}\right)}{2 t_{\mathrm{f}} E_{\mathrm{h}}}, \\
& k_{2}=\frac{\left(1+v_{\mathrm{c}}\right) r_{\mathrm{c}}\left[\left(1-2 v_{\mathrm{c}}\right) r_{\mathrm{c}}^{2}+r_{\mathrm{s}}^{2}\right]}{E_{\mathrm{c}} \varepsilon_{\mathrm{c}}\left(r_{\mathrm{c}}^{2}-r_{\mathrm{s}}^{2}\right)}, \\
& k_{3}=\frac{2\left(1-v_{\mathrm{c}}^{2}\right) r_{\mathrm{c}} r_{\mathrm{s}}^{2}}{E_{\mathrm{c}} \varepsilon_{\mathrm{c}}\left(r_{\mathrm{c}}^{2}-r_{\mathrm{s}}^{2}\right)}, \\
& m_{1}=\frac{\left(v_{\mathrm{c}}-v_{\mathrm{h}}\right) r_{\mathrm{c}},}{E_{\mathrm{c}} \varepsilon_{\mathrm{c}}\left(r_{\mathrm{c}}^{2}-r_{\mathrm{s}}^{2}\right)}, \\
& k_{5}=\frac{\left(1-v_{\mathrm{s}}^{2}\right) r_{\mathrm{s}}\left(r_{\mathrm{s}}+r_{\mathrm{c}}\right)}{2 t_{\mathrm{s}} E_{\mathrm{s}}}, \\
& k_{\mathrm{c}} \varepsilon_{\mathrm{c}}\left(r_{\mathrm{c}}^{2}-r_{\mathrm{s}}^{2}\right) \\
& \left.k_{\mathrm{s}}-v_{\mathrm{c}}\right) r_{\mathrm{s}} . \\
& \frac{\left(1+v_{\mathrm{c}}\right) r_{\mathrm{s}}\left[\left(1-2 v_{\mathrm{c}}\right) r_{\mathrm{s}}^{2}+r_{\mathrm{c}}^{2}\right]}{2}\left(1-v_{\mathrm{s}}^{2}\right) \\
& \left.m_{6}\right)
\end{aligned}
$$




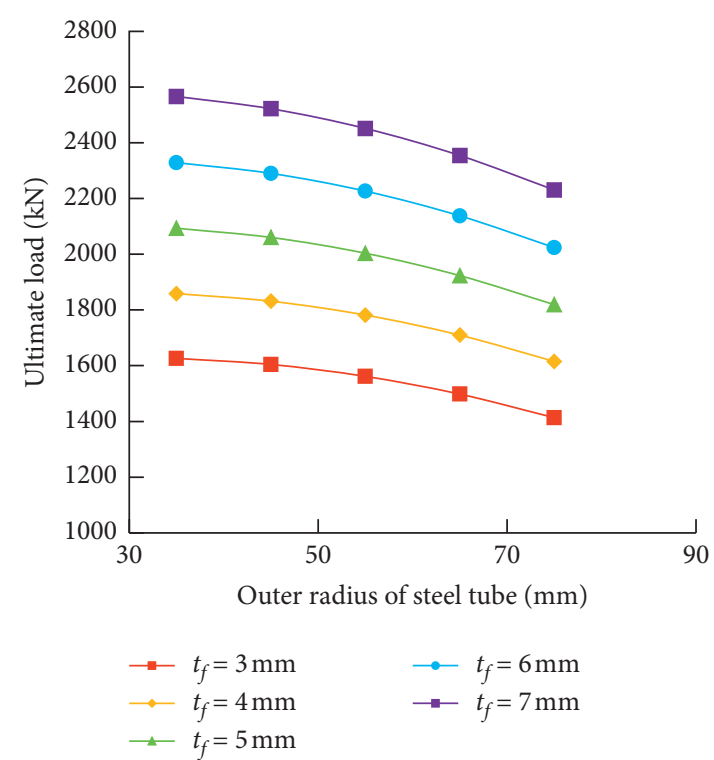

(a)

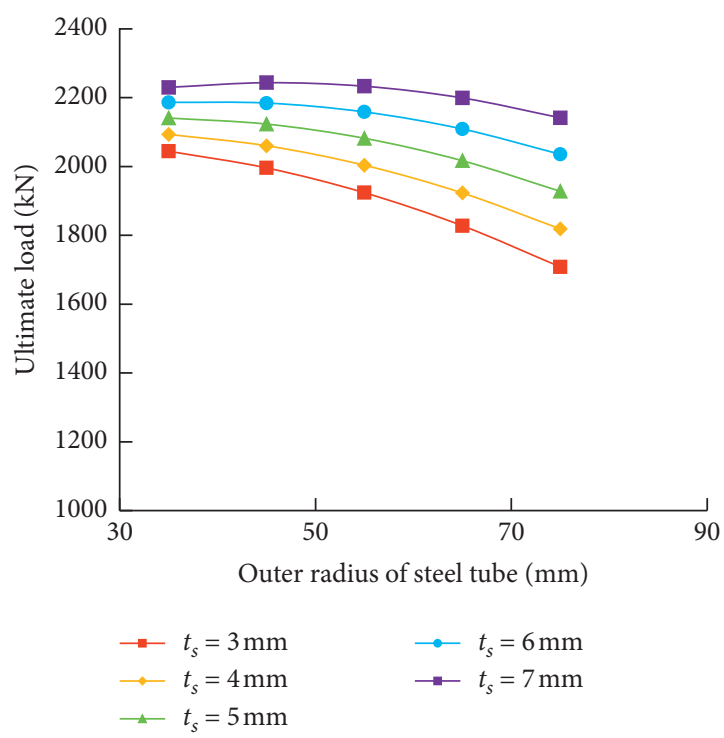

(b)

FIGURE 14: Influence of outer radius of the steel tube on ultimate load.

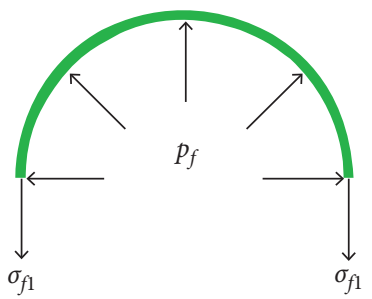

(a)

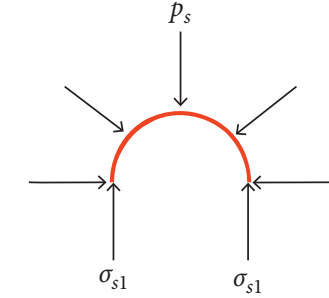

(b)

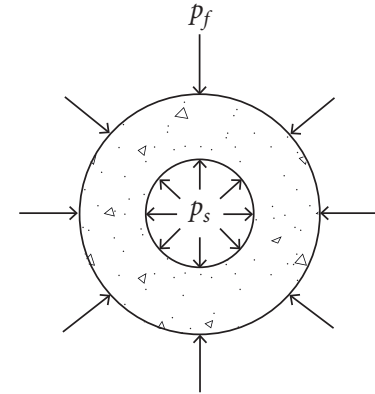

(c)

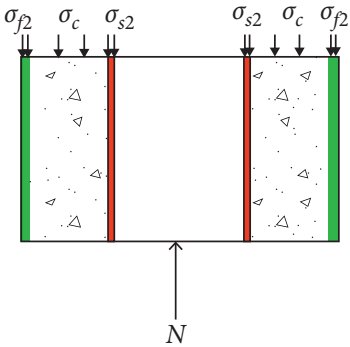

(d)

Figure 15: Force diagram of GGCS hollow column. (a) Glass fiber tube. (b) Steel tube. (c) Gangue concrete. (d) GGCS hollow column.

The failure of the glass fiber tube is based on the formula proposed by Azzi Hill [18].

$$
\begin{aligned}
A \sigma_{1}^{2}+B \sigma_{2}^{2}+C \sigma_{1} \sigma_{2}+D \tau_{12}^{2} & =1, \\
A & =\frac{1}{F_{1}^{2}}, \\
B & =\frac{1}{F_{2}^{2}}, \\
C & =-\frac{1}{F_{1}^{2}}, \\
D & =\frac{1}{S^{2}} .
\end{aligned}
$$

The stress of the glass fiber tube is obtained from the formula of stress axis.

$$
\begin{aligned}
\sigma_{1} & =\sigma_{\mathrm{f} 1} \cos ^{2} \theta+\sigma_{\mathrm{f} 2} \sin ^{2} \theta, \\
\sigma_{2} & =\sigma_{\mathrm{f} 1} \sin ^{2} \theta+\sigma_{\mathrm{f} 2} \cos ^{2} \theta, \\
\tau_{12} & =\left(\sigma_{\mathrm{f} 1}-\sigma_{\mathrm{f} 2}\right) \sin \theta \cos \theta,
\end{aligned}
$$

where $\sigma_{1}$ and $F_{1}$ are the stress and strength of glass fiber in main direction, respectively. $\sigma_{2}$ and $F_{2}$ are the stress and strength in main direction of matrix, respectively. $\tau_{12}$ and $S$ are the shear stress and shear strength in main direction of material, respectively. $\theta$ is the angle between winding direction of fiber and material main direction. Then, the following equation can be obtained. 
TABLE 5: Experiment results and calculated results.

\begin{tabular}{lccc}
\hline Specimens & $N^{\exp }(\mathrm{kN})$ & $N^{\text {cal }}(\mathrm{kN})$ & $N^{\text {cal }} / N^{\text {exp }}$ \\
\hline GGCS1 & 2021 & 2074 & 1.026 \\
GGCS2 & 1917 & 2074 & 1.082 \\
GGCS3 & 2064 & 2074 & 1.005 \\
GGCS4 & 1430 & 1604 & 1.122 \\
GGCS5 & 2111 & 2224 & 1.054 \\
GGCS6 & 1818 & 2074 & 1.141 \\
GGCS7 & 2297 & 2050 & 0.892 \\
\hline
\end{tabular}

Note. $N^{\text {exp }}$, experimental result; $N^{\text {cal }}$, the analytical result obtained based on the limit equilibrium method.

$$
\begin{aligned}
& {\left[A \sin ^{4} \theta+B \cos ^{4} \theta+(D-A) \sin ^{2} \theta \cos ^{2} \theta\right] \sigma_{\mathrm{f} 2}^{2}} \\
& \quad+\left[B \sin ^{4} \theta+A \cos ^{4} \theta+(D-A) \sin ^{2} \theta \cos ^{2} \theta\right] \sigma_{\mathrm{f} 1}^{2} \\
& \quad-\left[A \sin ^{4} \theta+B \cos ^{4} \theta+2(D-A-B) \sin ^{2} \theta \cos ^{2} \theta\right] \sigma_{\mathrm{f} 1} \sigma_{\mathrm{f} 2}=1 .
\end{aligned}
$$

Assume that

$$
\begin{aligned}
& a=A \sin ^{4} \theta+B \cos ^{4} \theta+(D-A) \sin ^{2} \theta \cos ^{2} \theta, \\
& b=A \sin ^{4} \theta+B \cos ^{4} \theta+2(D-A-B) \sin ^{2} \theta \cos ^{2} \theta, \\
& c=B \sin ^{4} \theta+A \cos ^{4} \theta+(D-A) \sin ^{2} \theta \cos ^{2} \theta .
\end{aligned}
$$

Then, the formula presented above can be simplified as

$$
a \sigma_{\mathrm{f} 2}^{2}-b \sigma_{\mathrm{f} 1} \sigma_{\mathrm{f} 2}+c \sigma_{\mathrm{f} 1}^{2}=1 \text {. }
$$

The $\sigma_{\mathrm{f} 2}$ can be derived by solving above equation, as shown in the following equation.

$$
\sigma_{\mathrm{f} 2}=\frac{b}{2 a} \sigma_{\mathrm{f} 1}-\frac{\sqrt{\left(b^{2}-4 a c\right) \sigma_{\mathrm{f} 1}^{2}+4 a}}{2 a} .
$$

The following equation can be derived by substituting (6) into (14).

$$
\sigma_{\mathrm{f} 2}=\frac{b r_{\mathrm{f}}}{2 a t_{\mathrm{f}}} p_{f}-\frac{\sqrt{\left(b^{2}-4 a c\right) r_{\mathrm{f}}^{2} p_{\mathrm{f}}^{2}+4 a t_{\mathrm{f}}^{2}}}{2 a t_{\mathrm{f}}} .
$$

The yield of gangue concrete is based on the three-way failure criterion [25] because the restraint effect of the inner steel tube on gangue concrete is smaller than that of the glass tube on gangue concrete, so $p_{s}$ is ignored. It is approximately considered that the restraint effect of gangue concrete is $\sigma_{\mathrm{c}}=p_{\mathrm{f}}$, and the formula is as follows:

$$
\sigma_{\mathrm{c}}=f_{\mathrm{c}}\left(1+K \frac{p_{\mathrm{f}}}{f_{\mathrm{c}}}\right),
$$

where the value $K$ is set according to the Fardis and Khalili model [26].

According to the von Mises yield condition, the steel tube is obtained.

$$
\sigma_{1}^{2}+\sigma_{1} \sigma_{2}+\sigma_{2}^{2}=f_{s}^{2}
$$

The following equation can be deduced by substituting (7) into (17).

$$
\sigma_{\mathrm{s} 2}=\sqrt{f_{\mathrm{s}}^{2}-\frac{3}{4}\left(\frac{p_{\mathrm{s}} r_{\mathrm{s}}}{t_{\mathrm{s}}}\right)^{2}}-\frac{p_{\mathrm{s}} r_{\mathrm{s}}}{2 t_{\mathrm{s}}}
$$

Substituting (15), (16), and (18) into equation (5), the following formula can be derived.

$$
N=A_{\mathrm{f}}\left(\frac{b r_{\mathrm{f}}}{2 a t_{\mathrm{f}}} p_{\mathrm{f}}-\frac{\sqrt{\left(b^{2}-4 a c\right) r_{\mathrm{f}}^{2} p_{\mathrm{f}}^{2}+4 a t_{\mathrm{f}}^{2}}}{2 a t_{\mathrm{f}}}\right)+A_{\mathrm{c}} f_{\mathrm{c}}\left(1+K \frac{p_{\mathrm{f}}}{f_{\mathrm{c}}}\right)+A_{s}\left(\sqrt{f_{\mathrm{s}}^{2}-\frac{3}{4}\left(\frac{p_{\mathrm{s}} r_{\mathrm{s}}}{t_{\mathrm{s}}}\right)^{2}}-\frac{p_{\mathrm{s}} r_{\mathrm{s}}}{2 t_{\mathrm{s}}}\right)
$$

5.2. Formula Validation. In order to verify the reliability of the proposed analytical formula of GGCS hollow column which is established based on the limit equilibrium method, the analytical results are compared with the experimental results, as given in Table 5. It can be concluded that the average error is 1.046 and the mean square error is 0.090 . It can be concluded that the calculated results are in good agreement with the experimental results, which indicates that the formula established in this study is reasonable.

\section{Conclusion}

The compression behavior of GGCS hollow columns is investigated in this study. The bearing capacity is studied by nonlinear analysis program, experimental verification, and theoretical analysis. A nonlinear analysis program of GGCS hollow column under axial compression is proposed, and the effects of the glass fiber tube, thickness, and radius of the steel tube on the axial compression performance of GGCS hollow column are systematically studied. The conclusions can be summarized as follows:

(1) The reliability of the nonlinear analysis program of GGCS hollow column under axial compression is verified by experiments, which shows that it is feasible to use the program to analyze the axial compression performance of GGCS hollow columns

(2) The analytical formula of axial bearing capacity of GGCS hollow column is established, which can provide references for the design and calculation of the new hollow column 
(3) The axial bearing capacity of GGCS hollow column increases linearly with the increase of the thickness of the glass fiber tube and steel tube, but not linearly with the decrease of the outer radius of the steel tube

(4) With the increase of steel tube thickness, the stiffness of GGCS hollow column increases. With the increase of glass fiber tube thickness, the restraint effect of the glass fiber tube on gangue concrete is enhanced.

\section{Data Availability}

The data used to support the findings of this study are available from the corresponding author upon request.

\section{Conflicts of Interest}

The authors declare that they have no conflicts of interest.

\section{Acknowledgments}

This work was supported by the Liaoning Provincial Department of Education Youth Science and Technology Talent Seedling Project (LJ2020QNL006) and Discipline Innovation Team of Liaoning Technical University (LNTU20TD-12).

\section{References}

[1] D. Wu, Y. Hou, T. Deng, Y. Chen, and X. Zhao, "Thermal, hydraulic and mechanical performances of cemented coal gangue-fly ash backfill," International Journal of Mineral Processing, vol. 162, pp. 12-18, 2017.

[2] M. W. Aiguo, Y. Zhu, H. Xu et al., "Research progress on coal gangue aggregate for concrete," Bulletin of the Chinese Ceramic Society, vol. 38, no. 7, pp. 2076-2086, 2019.

[3] M. Xiao, F. Ju, and Z.-q. He, "Research on shotcrete in mine using non-activated waste coal gangue aggregate," Journal of Cleaner Production, vol. 259, Article ID 120810, 2020.

[4] H. Ma, H. Zhu, C. Wu, H. Chen, J. Sun, and J. Liu, "Study on compressive strength and durability of alkali-activated coal gangue-slag concrete and its mechanism," Powder Technology, vol. 368, pp. 112-124, 2020.

[5] Y. Wang, Y. Tan, Y. Wang, and C. Liu, "Mechanical properties and chloride permeability of green concrete mixed with fly ash and coal gangue," Construction and Building Materials, vol. 233, Article ID 117166, 2020.

[6] S. Gao, G. Zhao, L. Guo, L. Zhou, and K. Yuan, "Utilization of coal gangue as coarse aggregates in structural concrete," Construction and Building Materials, vol. 268, Article ID 121212, 2021.

[7] J. Li and J. Wang, "Comprehensive utilization and environmental risks of coal gangue: a review," Journal of Cleaner Production, vol. 239, Article ID 117946, 2019.

[8] Q. Sun, S. Tian, Q. Sun et al., "Preparation and microstructure of fly ash geopolymer paste backfill material," Journal of Cleaner Production, vol. 225, pp. 376-390, 2019.

[9] R. Jamatia and A. Deb, "FRP confined hollow columns under axial compression," Composite Structures, vol. 236, Article ID 11857, 2020.

[10] M. F. M. Fahmy and Z. Wu, "Evaluating and proposing models of circular concrete columns confined with different
FRP composites," Composites Part B: Engineering, vol. 41, no. 3, pp. 199-213, 2010.

[11] B. Purushotham Reddy, P. Alagusundaramoorthy, R. Sundaravadivelu et al., "Retrofitting of RC piles using GFRP composites," KSCE Journal of Civil Engineering, vol. 13, no. 1, pp. 39-47, 2009.

[12] R. Realfonzo and A. Napoli, "Concrete confined by FRP systems: confinement efficiency and design strength models," Composites Part B: Engineering, vol. 42, no. 4, pp. 736-755, 2011.

[13] J. G. Teng, T. Yu, and Y. L. Wong, "Behavior of hybrid FRPconcrete-steel double-skin tubular columns," in Proceedings of the 2nd International Conference of FRP Composites in Civil Engineering, pp. 811-818, Adelaide, Australia, September 2004.

[14] T. Yu, S. Zhang, L. Huang, and C. Chan, "Compressive behavior of hybrid double-skin tubular columns with a large rupture strain FRP tube," Composite Structures, vol. 171, pp. 10-18, 2017.

[15] S. B. Talaeitaba, M. Halabian, and M. Ebrahim Torki, "Nonlinear behavior of FRP-reinforced concrete-filled double-skin tubular columns using finite element analysis," ThinWalled Structures, vol. 95, pp. 389-407, 2015.

[16] J. L. Zhao, J. G. Teng, T. Yu et al., "Behavior of large-scale hybrid FRP-concrete-steel double-skin tubular beams with shear connectors," Journal of Composites for Construction, vol. 20, no. 5, Article ID 04016015, 2016.

[17] T. Yu, Y. L. Wong, J. G. Teng, S. L. Dong, and E. S. Lam, "Flexural behavior of hybrid FRP-concrete-steel double-skin tubular members," Journal of Composites for Construction, vol. 10, no. 5, pp. 443-452, 2006.

[18] T. Ozbakkaloglu and B. A. Louk Fanggi, "FRP-HSC-steel composite columns: behavior under monotonic and cyclic axial compression," Materials and Structures, vol. 48, no. 4, pp. 1075-1093, 2015.

[19] T. Yu, B. Zhang, Y. B. Cao, and J. G. Teng, "Behavior of hybrid FRP-concrete-steel double-skin tubular columns subjected to cyclic axial compression," Thin-Walled Structures, vol. 61, pp. 196-203, 2012.

[20] Z. Zhao, H. Zhang, L. Xian, and H. Liu, "Tensile strength of Q345 steel with random pitting corrosion based on numerical analysis," Thin-Walled Structures, vol. 148, Article ID 106579, 2020.

[21] M. Samaan, A. Mirmiran, and M. Shahawy, "Model of concrete confined by fiber composites," Journal of Structural Engineering, vol. 124, no. 9, pp. 1025-1031, 1998.

[22] G. Lu, L. Ye, C. Yang et al., "Research on stress-strain relation of concrete confined with FRP tubes," Engineering Mechanics, vol. 23, no. 9, pp. 98-103, 2006.

[23] S. Zhong, The concrete-filled Steel Tubular Structures, Heilongjiang Science and Technology Press, Heilongjiang, China, 1994.

[24] J. Wen, Research on the Mechanical Properties of Axially Loaded GFRP-Strength Concrete-Steel Double-Skin Tubular Columns, Notheastern University, Boston, MA, USA, 2011.

[25] R. M. Jones, Mechanics of Composite Material, CRC Press, Boca Raton, FL, USA, 2nd edition, 1999.

[26] M. N. Fardis and H. Khalili, "Concrete encased in fiberglassreinforced plastic," Journal of the American Concrete Institute, vol. 78, no. 6, pp. 440-446, 1981. 